\title{
Fluctuación prefijal en el gallego-portugués y en el castellano medievales
}

\section{Prefixal fluctuation in Galician-Portuguese and Medieval Castilian}

\author{
Graça Rio-Torto \\ Universidade de Coimbra (Portugal) \\ riotorto@fl.uc.pt \\ Mailson Lopes \\ Universidade Federal da Bahia (Brasil) \\ mailson.lopes@ufba.br
}

Recibido o 03/05/2018

Aceptado o 28/01/2019

\section{Resumen}

En el gallego-portugués medieval y en el castellano antiguo coexisten verbos corradicales con y sin prefijo (acuydar y cuydar, esguardar y guardar), semánticamente equivalentes o aproximados. Paralelamente, en el portugués y en el castellano actuales hay formas como agradecer, otrora no prefijados (gradecer). Ambos procesos de pérdida o añadidura prefijales actúan involucrados en flujos de variación y cambio, resultando comúnmente en el solapamiento de una de las voces, durante o tras el medievo. Se propone una reflexión sobre las motivaciones de estos diferentes trayectos prefijales, considerándose la estructura de la base verbal, la naturaleza del prefijo, en el latín y en romance, y factores de naturaleza externa que pueden estar en la base de la coexistencia, durante varios siglos, de dos formas corradicales o de la pérdida de tal convivencia.

\section{Palabras clave}

Gallego-portugués medieval; castellano antiguo; variación y cambio; fluctuación prefijal

\section{Sumario}

1. Introducción. 2. Fluctuación prefijal en el gallego-portugués y en el castellano medievales. 2.1. Equivalencia semántica plena. 2.1.1. Equivalencia semántica plena con pervivencia de ambas formas hasta el presente. 2.1.2. Equivalencia semántica plena con prevalencia de la forma prefijada. 2.1.3. Equivalencia semántica plena con prevalencia de la forma no prefijada. 2.1.4. Equivalencia semántica plena con obsolescencia de ambas formas. 2.2. Diferenciación semántica plena. 2.3. Equivalencia y distinción semántica parciales. 2.3.1. La forma prefijada es la más plurisignificativa. 2.3.2. La forma no prefijada es la más plurisignificativa. 3. Consideraciones generales sobre el fenómeno. 4. Conclusión.

\begin{abstract}
In Galician-Portuguese and in Old Castilian the coexistence of verbs with and without prefix (acuydar and cuydar, esguardar and guardar) that are semantically equivalent or with close meanings is attested. At the same time, in the current Spanish and Portuguese there are words like agradecer, not previously prefixed (gradecer). Both processes of prefix loss and prefix addition operate within the framework of the fluxes of variation and change of that period, commonly resulting in the overlap of one of the words during or after the Middle Ages. We propose to investigate the motivations of these different prefix trajectories, considering the structure of the verbal base, the nature of the prefix, in Latin and in Romance, and the external factors that support (i) the coexistence, during several centuries, of both forms sharing the same root or (ii) the loss of such coexistence.
\end{abstract}

\section{Keywords}

Galician-Portuguese; Old Castilian; variation and change; prefixal fluctuation

\section{Contents}

1. Introduction. 2. Prefixal fluctuation in Galician-Portuguese and Medieval Castilian. 2.1. Full semantic equivalence. 2.1.1. Full semantic equivalence with survival of both forms until the present. 2.1.2. Full semantic equivalence with prevalence of the prefixed form. 2.1.3. Full semantic equivalence with prevalence of the non-prefixed form. 2.1.4. Full semantic equivalence with obsolescence of both forms. 2.2. Full semantic differentiation. 2.3. Parcial semantic equivalence and parcial semantic distinction. 2.3.1. The prefixed form is the most plurisignificant. 2.3.2. The non-prefixed form is the most plurisignificant. 3. General comments on the phenomenon. 4. Conclusion. 


\section{Introducción}

L As lenguas iberorrománicas se encuentran en los siglos XIII y XIV en su periodo de registro primitivo en la modalidad escrita, en una fase constitutiva de su propia elaboración y de soporte de las prácticas sociales, funcionando como vehículo de vasta producción jurídica y literaria. En este contexto de emergencia y consolidación de la escritura vernácula, los romances ibéricos no se regían por una rígida normativización lingüístico-ortográfica balizadora o por patrones de uso prestigiado asociados a un control gramatical prescriptivo (Mattos \& Silva 2010 [1989]; 2006; 2008a; 2008b), lo que daba margen a un polimorfismo acentuado (Lapesa 1981; Maia 2002) y a una pujante diversidad en el registro de los constituyentes léxicos y gramaticales, aunque no de forma anárquica ni sin algunas normas dominantes (Menéndez Pidal 2005).

Este trabajo describe y analiza algunos casos de coexistencia de verbos (o deverbales) equivalentes con y sin prefijo en el gallego-portugués y en el castellano de los siglos XIII-XIV (con o sin el solapamiento de una de las formas del par corradical), así como procesos de pérdida o añadidura prefijales, comparándose derivados medievales y sus correspondencias en el periodo contemporáneo. Para ello, se seleccionaron algunas voces prefijadas en un corpus representativo de 56 textos (jurídico-notariales, poéticos y en prosa literaria), 28 para cada uno de los sistemas lingüísticos abordados $^{1}$. Se describirán para cada palabra prefijada y no prefijada de los respectivos pares

1. Los textos gallego-portugueses consultados en el Corpus Informatizado do Português Medieval (CIPM; cipm.fcsh.unl.pt) acompañados de su código y datación son los siguientes: Textos Notariais in Clíticos na História do Português (TNC13 - s. XIII; TNC14 - s. XIv), Textos Notariais in História do Galego-Português (TNH13 - s. XIII; TNH14 - s. XIv), Textos Notariais do Arquivo de Textos do Português Antigo (TNAT13 - s. XIII; TNAT14 - s. XIV), Chancelaria D. Afonso III (CDA3 - s. XIII), Chancelaria D. Afonso IV (CDA4 - s. XIv), Dos Costumes de Santarém (DCS13 - s. XIII; DCS14 - s. XIv), Foros de Garvão (FG13 - s. XIII; FG14 - s. XIV), Tempos dos Preitos (TP - s. XIII), Foro Real, de Afonso X (FR - s. XIII), Primeyra Partida, de Afonso X (PP - s. XIV), Vidas de Santos de um Manuscrito Alcobacense (VSMA - s. XIV), Diálogos de São Gregório (DSG - s. XIV), Arte de Trovar (AT - s. XIV), Crónica Geral de Espanha (CGE - s. XIV), Livro de Montaria (LM - s. XIV), Narrativa de livro de linhagens (NLL - s. XIV), Orto do Esposo (OE - s. XIv), Cantigas de Amigo (CAMI - s. XIII), Cantigas de Santa Maria (CSM - s. XIII), Cantigas de Escárnio e Maldizer (CEM13 - s. XIII; CEM14 - s. XIV) y Cantigas de Amor (CA13 - s. XIII; CA14 - s. XIV). Los textos castellanos, consultados en la Biblioteca Digital de Textos del Español Antiguo (http://www.hispanicseminary.org/textconc-es.htm) son estos: Fuero Viejo de Alcalá (FVA - s. XIII), Libro de las leyes (LEY - s. XIII), Fuero Juzgo (FJZ - s. XIII), Espéculo (SPC - s. XIV), Leyes del estilo (AC3 - s. XIV), Fuero Real (FRL - s. XIV), Moamyn - Libro de las animalias (MOA - s. XIII), Judizios de las estrellas (JUZ - s. XIII), Picatrix de Alfonso X (PIC - s. XIII), Libro de las cruzes (CRZ - s. XIII), Lapidarios de Alfonso X(LAP - s. XIII), Tablas de Zarquiel (ZRQ - s. $\mathrm{XIII})$, Libro de las formas y de las imágenes (YMG - s. XIII), Libros del saber de astronomía (AST - s. XIII), Libros de ajedrez, dados y tablas (ACE - s. XIII), Fuero de Salamanca (FSA - s. XIV), Ordenamiento de Alcalá (OA1 - s. XIV), Fueros de Castiella (CAS - séc. XIV), Visita y consejo de médicos (VIS - s. XIV), Estoria de España I (EE1 - s. XIII), La Fazienda de Ultramar (LFU - s. XIII), Biblia romanceada E8 (BRE8 - s. XIII), General Estoria (GEE - s. XIII), Poema de Mio Cid (CID - s. XIII), Libro de Apolonio 
corradicales su estructura, su étimo (o el étimo de la base) y su sentido en el contexto de uso.

Para cada una de las lenguas se analizarán algunos pares corradicales distribuidos por tres categorías, con base en la equivalencia/diferenciación semántica total o parcial entre ellas. Se seleccionaron los pares en función de la idéntica estructura en ambas lenguas (cuando posible), con el intento de lograr una comparación más precisa entre ellos. Las dificultades en encontrar ejemplos de pares corradicales que sirvieran a una misma clase de fluctuación para ambas lenguas hacen que no en todas las categorías haya la comparación estricta entre un mismo par léxico corradical con y sin prefijo ${ }^{2}$.

La observación de los datos analizados llevó a la demarcación de las siguientes categorías y subcategorías para la fluctuación —en régimen de coocurrencia y/o de concurrencia- entre las formas, tanto para el gallego-portugués medieval (GP) como para el castellano antiguo (CA).

\begin{tabular}{|c|c|}
\hline \multirow{4}{*}{$\begin{array}{l}\text { Equivalencia semántica } \\
\text { plena }\end{array}$} & $\begin{array}{l}\text { Con conservación de ambas formas en la evolución de la lengua y con } \\
\text { rasgos diatópicos, diastráticos y/o diafásicos en una o en las dos formas }\end{array}$ \\
\hline & Con prevalencia de la forma prefijada en la historia de la lengua \\
\hline & Con prevalencia de la forma no prefijada en la historia de la lengua \\
\hline & Con obsolescencia de ambas formas en la historia de la lengua \\
\hline $\begin{array}{l}\text { Diferenciación } \\
\text { semántica plena }\end{array}$ & $\begin{array}{l}\text { A causa de movimientos metafóricos o metonímicos o independiente } \\
\text { de ellos }\end{array}$ \\
\hline \multirow{2}{*}{$\begin{array}{c}\text { Equivalencia y } \\
\text { distinción semánticas } \\
\text { parciales }\end{array}$} & Forma prefijada más plurisignificativa que la no prefijada \\
\hline & Forma no prefijada más plurisignificativa que la prefijada \\
\hline
\end{tabular}

(APO - s. XIII), Libro de Alexandre (ALX - s. XIII), Obras de Gonzalo de Berceo (BER - s. XIII), Libro de buen amor $G$ (BAG - s. XIV).

2. No se ha encontrado hasta ahora ningún ejemplo de un mismo par léxico de ambos sistemas lingüísticos que encaje en la categoría "Equivalencia semántica plena con obsolescencia de ambas formas".

3. Se conjeturó al principio la distinción entre dos subclases en el interior de esta categoría -(i) fluctuación de voces semánticamente equivalentes y perdurables en la evolución de la lengua con rasgos diatópicos, diastráticos y/o diafásicos en una o en las dos formas; (ii) igual fluctuación, pero sin marcas de orden diatópico, diastrático o diafásico entre las voces corradicales_-; como se encontró un número ínfimo de ejemplos para la segunda subcategoría (dependurar pendurar, para el portugués; acostumbrar - costumbrar, para el castellano), se decidió considerar únicamente la primera de ellas, indudablemente comprobable en las lenguas estudiadas. 
Tabla 1. Clases de relaciones semánticas observables entre pares de unidades léxicas corradicales

\section{Fluctuación prefijal en el gallego-portugués y en el castellano medievales}

\subsection{Equivalencia semántica plena}

\subsubsection{Equivalencia semántica plena con pervivencia de ambas formas hasta el presente}

La primera situación de fluctuación es la de equivalencia semántica absoluta entre los miembros de la pareja corradical, con la pervivencia de ambas formas en la historia de la lengua. Tal uso puede, o no, ser marcado diastrática, diafásica y/o diatópicamente. Sin embargo, son muy raros los pares corradicales cuyo uso no presenta alguna de esas marcas.

(1) assemelhar ${ }^{4}-$ semelhar (GP) ${ }^{5} /$ assemejar $^{6}-$ semejar $^{7}(\mathrm{CA})$

En teoría, se puede pensar en un cuadro de equivalencia entre las variantes con y sin prefijo que se mantienen en fluctuación, desde el gallego-portugués/castellano antiguos hasta la época actual; pero en realidad esos pares corradicales con equivalencia semántica plena entre sus miembros son muy raros y presentan una vitalidad muy escasa.

De todos los datos analizados solo se encontró un único caso simultáneamente aplicable al GP y al CA de un mismo par léxico de equivalencia semántica plena y dotado de pervivencia de entrambas formas hasta el presente: asemellar / asemejar semellar / semejar. En los dos sistemas lingüísticos en cuestión los miembros del par significaban en el pasado 'tener semejanza, mostrarse semejante, parecerse a algo o a alguien'. Los ejemplos a continuación lo demuestran (los dos primeros son del GP; los últimos, del CA):

[...] mays por averem estas animalias delles as calidades que am que assemelharom os signos, mays que todallas outras que son so o ceo. (FR).

4. Del GP A- + -SEMELHAR < lat. * SIMILIĀRE < lat. SǏMǏLIS.

5. Del lat. SIMILIĀRE $<$ lat. SIMMILLIS.

6. Del CA A- + -semejar < CA SEMeja < lat. Similia, pl. de simĭle.

7. Del CA semeja < lat. similia, pl. de simĭle. 
E sse nó poder monstrar outor peyt(e) esta pea dub(ra)da, ca ladrô semelha $\mathrm{q}($ uẽ) a cousa do furto (con)para que sabe do ladrô. (PP).

E el sabio que sopiere asemeiar. \& conuenir. las cosas de suso con las de yuso; uerifican se sus dichos \& sos asmamientos \& sus fechos con el poder de dios. (JUZ).

Ruego-te, madre, que non quieras semejar a las mugeres en flaqueza de coraçon [...]. (Bocados de oro, s. XIII - CORDE)

Los datos del CPMD ${ }^{8}$ apuntan hacia un uso considerable de la forma no prefijada en el GP, desplazada tras ese periodo por su corradical con prefijo, concretamente a partir del s. XVII'

\begin{tabular}{llccccccccc}
\hline \multicolumn{1}{l}{ CPMD - https://www.corpusdoportugues.org/ } \\
\hline \multirow{3}{*}{ assemelhar } & sección & $s 13$ & $s 14$ & $s 15$ & $s 16$ & $s 17$ & $s 18$ & $s 19$ & $s 20$ \\
& ocurrencias & 0 & 0 & 0 & 0 & 5 & 4 & 2 & 12 \\
& por millón & 0.00 & 0.00 & 0.00 & 0.00 & 1.53 & 1.83 & 0.21 & 0.59 \\
\hline \multirow{3}{*}{ semelhar } & sección & $s 13$ & $s 14$ & $s 15$ & $s 16$ & $s 17$ & $s 18$ & $s 19$ & $s 20$ \\
& ocurrencias & $s 13$ & $s 14$ & $s 15$ & $s 16$ & $s 17$ & $s 18$ & $s 19$ & $s 20$ \\
& por millón & 9 & 4 & 23 & 2 & 0 & 0 & 0 & 1 \\
\hline
\end{tabular}

Tabla 2. Assemelhar y semelhar en el CPMD

En cuanto al castellano, a partir de los datos del CEMD ${ }^{10}$, se nota igualmente una variación, pero con una especificidad respecto al GP: mientras que en este se da el alzamiento de la forma prefijada sobre la no prefijada, en aquel se mantiene como más frecuente la voz sin prefijo frente a su corradical:

8. Davies, Mark (en línea), Corpus do Português.

9. El vocablo no prefijado sigue en uso en la lengua, pero tal vez con algún rasgo de [+ erudito], pormenor del que no se informa en los diccionarios consultados.

10. Mark Davies, Corpus del Español. 


\begin{tabular}{llcccccccc}
\hline \multicolumn{10}{c}{ CEMD - https://www.corpusdelespanol.org/ } \\
\hline \multirow{3}{*}{ asemejar } & sección & $s 13$ & $s 14$ & $s 15$ & $s 16$ & $s 17$ & $s 18$ & $s 19$ & $s 20$ \\
& ocurrencias & 1 & 0 & 17 & 3 & 0 & 1 & 3 & 1 \\
& por millón & 0.15 & 0.00 & 2.08 & 0.18 & 0.00 & 0.10 & 0.16 & 0.04 \\
\hline \multirow{3}{*}{ semejar } & sección & $s 13$ & $s 14$ & $s 15$ & $s 16$ & $s 17$ & $s 18$ & $s 19$ & $s 20$ \\
& ocurrencias & 38 & 27 & 62 & 7 & 3 & 2 & 6 & 3 \\
& por millón & 5.66 & 10.11 & 7.60 & 0.41 & 0.24 & 0.20 & 0.31 & 0.13 \\
\hline
\end{tabular}

Tabla 3. Asemejar y semejar en el CEMD

La segunda situación de oscilación engloba casos en los que un par léxico corradical sinonímico se perpetúa, pero recibiendo evidentes marcas de uso en uno de sus miembros, como en los siguientes ejemplos:

(2) ajuntar ${ }^{11}-$ juntar $^{12} /$ aiuntar ${ }^{13}-$ iuntar $^{14}$

En los corradicales ajuntar - juntar, se nota igualmente una variación, como en los fragmentos de los siguientes textos del GP, ambos de su primera sincronía arcaica (s. XIII-XIV), en los cuales los verbos denotan el mismo sentido, el de 'reunir, congregar, juntar':

E depois que o Cide morreo, venceo rei Bucar outra vez, com todo o poder que pode ajuntar d'Africa. (NLL)

Nen quero de dizer leixar / de como foy chegada / a graça que Deus enviar / lle quis, atan grãada, / que por el esforçada / foy a companna que juntar / fez Deus, e enssinada, / de Spirit' avondada, / por que souberon pregar / logo sen alongada. (CSM)

En un gran número de textos, tanto del $\mathrm{DDGM}^{15}$ como del $\mathrm{DVPM}^{16}$, hay innumerables ejemplos de dicha fluctuación, lo que corrobora la interpretación de los datos en el conjunto documental empírico que fundamenta esta exposición. Tal coocurrencia se ha mantenido hasta hoy en el gallego y en el portugués, pero, al menos en esta última lengua, la forma prefijada es la menos frecuente y se asocia a determinados

11. Del GP A- + -JUnt(o) - + -A- + -R < lat. JUnCtUS, part. pas. de JUNGĔRE.

12. Del GP junto $<$ lat. Junctus, part. pas. de JUnGĚre.

13. Del CA A- + -JUnT(o) - + -A- + -R < lat. JUNCTUS, part. pas. de JUNGĚRe.

14. Del CA junto < lat. junctus, part. pas. de jungere.

15. González Seoane (coord.) (en línea).

16. Xavier / Crispim / Vicente (orgs.) (en línea). 
registros diatópicos, diafásicos y/o diastráticos, o sea, es marcada. Otros casos análogos, para el GP, serían alembrar - lembrar, alimpar limpar, arrebentar rebentar, assoprar - soprar, avoar - voar ${ }^{17}$.

Con respecto al CA, además de la forma juntar ${ }^{18}$, se registra también su corradical prefijada, señalando la convivencia entre las formas, a ejemplo de lo que ocurre en el FJZ y en el CAS (s. XIV), en que denota, respectivamente, los sentidos de 'juntar, reunir, congregar':

Todos los ob $<$ is $>$ pos nos aiuntamos. En el no $<$ m $>$ bre de $n<$ uest $>$ ro sen $<\mathrm{n}>$ or en uno. en la cipdat de toledo por el mandado del Rey.

o de 'amancebarse':

Et establesco \& do por fuero $\mathrm{q}<$ ue $>$ sy alguna / $\mathrm{ma}<\mathrm{n}>$ ceba sin voluntad de sus parie $<\mathrm{n}>$ tes. o de sus çer-ca $<\mathrm{n}>$ nos cormanos casare $\mathrm{co}<\mathrm{n}>$ algun varon. $\mathrm{O}$ se aiu $<n>$-tare con el por $\mathrm{q}<\mathrm{u}><<\mathrm{a}>>\mathrm{l} \mathrm{q}<\mathrm{u}><<\mathrm{i}>>$ er aiu $<\mathrm{n}>$ tamiento pesando alos mas delos parie $<\mathrm{n}>$ tes.

En el CORDE ${ }^{19}$, en los siglos XIII y XIV, al lado de las formas ayuntarlajuntarl aiuntar, ocurren las formas yuntar/juntarliuntar, todas ellas denotando los dos sentidos mencionados, en una clara situación de fluctuación entre las voces corradicales. Sin embargo, a diferencia de lo que caracteriza los ejemplos en (1), en el par ajuntar - juntar la forma prefijada es hoy día marcada diastrática o diafásicamente, como un vulgarismo (en las dos acepciones) o con usos propios de la niñez (con una acepción de 'tener trato amistoso o de camaradería con alguien'), según el DLE/RAE ${ }^{20}$. Esa situación de equivalencia entre los corradicales, que perdura en la lengua pero con alguna marcación de uso, se observa también en pares como ayuntado - yuntado, amostrar mostrar, aproueitar proueitar, endemoniado demoniado.

Los datos del CPMD y del CEMD corroboran la variación antedicha, demostrando, además, algo de la vitalidad que la caracteriza en la evolución de las lenguas, con una clara victoria de la forma no prefijada (desde el período arcaico para el castellano; desde el s. xx para el portugués):

17. De acuerdo con los registros, acepciones y dataciones señalados en Cunha (2010).

18. No se reproduce aquí la forma no prefijada, pero es patente que se hace presente en la lengua arcaica y ello lo atestigua el CORDE, con cerca de una centena de casos (s. XIII-XIV) en que yuntar/ juntar/iuntar denotan las mismas acepciones que sus corradicales prefijadas.

19. Real Academia Española, Corpus Diacrónico del Español.

20. Real Academia Española, Diccionario de la lengua española. 


\begin{tabular}{llccccccccc}
\hline \multicolumn{1}{c}{ CPMD - https://www.corpusdelportugues.org/ } \\
\hline \multirow{3}{*}{ ajuntar } & sección & $s 13$ & $s 14$ & $s 15$ & $s 16$ & $s 17$ & $s 18$ & $s 19$ & $s 20$ \\
& ocurrencias & 4 & 34 & 89 & 178 & 209 & 119 & 76 & 22 \\
& por millón & 7.26 & 26.40 & 31.29 & 41.08 & 63.87 & 54.35 & 7.81 & 1.09 \\
\hline \multirow{3}{*}{ juntar } & sección & $s 13$ & $s 14$ & $s 15$ & $s 16$ & $s 17$ & $s 18$ & $s 19$ & $s 20$ \\
& ocurrencias & 10 & 20 & 43 & 30 & 27 & 26 & 66 & 380 \\
& por millón & 18.15 & 15.53 & 15.12 & 6.92 & 8.25 & 11.88 & 6.78 & 18.75 \\
\hline
\end{tabular}

Tabla 4. Ajuntar y juntar en el CPMD

\begin{tabular}{llccccccccc}
\hline \multicolumn{1}{c}{ CEMD - https://www.corpusdelespanol.org/ } & & \\
\hline \multirow{3}{*}{ aiuntar } & sección & $s 13$ & $s 14$ & $s 15$ & $s 16$ & $s 17$ & $s 18$ & $s 19$ & $s 20$ \\
& ocurrencias & 20 & 0 & 30 & 0 & 0 & 0 & 0 & 0 \\
& por millón & 2.98 & 0.00 & 3.68 & 0.00 & 0.00 & 0.00 & 0.00 & 0.00 \\
\hline \multirow{4}{*}{ ajuntar } & sección & $s 13$ & $s 14$ & $s 15$ & $s 16$ & $s 17$ & $s 18$ & $s 19$ & $s 20$ \\
& ocurrencias & 14 & 1 & 4 & 24 & 1 & 1 & 1 & 0 \\
& por millón & 2.08 & 0.37 & 0.49 & 1.41 & 0.08 & 0.10 & 0.05 & 0.00 \\
\hline \multirow{3}{*}{ juntar } & sección & $s 13$ & $s 14$ & $s 15$ & $s 16$ & $s 17$ & $s 18$ & $s 19$ & $s 20$ \\
& ocurrencias & 15 & 42 & 150 & 825 & 352 & 282 & 133 & 120 \\
& por millón & 2.23 & 15.73 & 18.38 & 48.43 & 28.51 & 28.73 & 6.89 & 5.26 \\
\hline
\end{tabular}

Tabla 5. Aiuntar, ajuntar y juntar en el CEMD

\subsubsection{Equivalencia semántica plena con prevalencia de la forma prefijada}

Otra posibilidad de fluctuación es aquella en la que hay una equivalencia semántica absoluta entre los miembros del par corradical en el periodo arcaico, pero con la posterior prevalencia de una de las formas. Hay casos en los que sobrevive la forma prefijada y otros en los que se nota la pervivencia de la no prefijada. En una y otra situación la fluctuación acaba por desintegrarse con el paso del tiempo. Se pueden ver a continuación algunos ejemplos para cada caso.

(3) aconselhar $^{21}-$ conselhar $^{22}$ / aconsejar ${ }^{23}-$ consejar $^{24}$

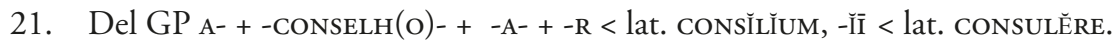

22. Del GP CONSELHo < lat. CONSĬLIUUM, -İİ $<$ lat. CONSUlĚre.

23. Del CA A- + -CONSEJ(O) - + -A- + -R < lat. CONSĬLĬUM, -ĬĪ < lat. CONSUlĔRE.

24. Del CA CONSEJo < lat. CONSĬLĬUM, -Ĭİ $<$ lat. CONSUlĔRE. 
Convivían en el GP las variantes aconselhar conselhar, bajo una atmósfera de auténtica sinonimia, atestiguada, a ejemplificación, en los fragmentos siguientes:

A Virgen Santa Maria; | e outro dia fillou / seu camỹ', e assi yndo, | un ome cego achou / que a Santiago ya; | mas ela Il' aconssellou / que fosse por Vila-Sirga, se quissese lum' aver. (CSM)

E ainda vos conselharei al, / por que vos amo mui de coraçon: / que nunca voz en dia d'Acenson / tenhades, nen em dia de Natal, / nen doutras festas de Nostro Senhor / nen de seus santos, ca ei gran pavor / de vos vĩir mui toste deles mal. (CEM13)

Los testimonios del DDGM, del CIPM y del TMILG ${ }^{25}$ confirman esa alternancia sinonímica entre las formas con y sin prefijo, con una innegable predominancia de la última en todo el periodo medieval (pero no desde el s. Xvir hasta la actualidad, período en el que la variante no prefijada cae en desuso), lo que se refleja asimismo en los datos del CPMD:

\begin{tabular}{llcccccccc}
\hline \multicolumn{10}{l}{ CPMD - https://www.corpusdoportugues.org/ } \\
\hline \multirow{3}{*}{ aconselhar } & sección & $s 13$ & $s 14$ & $s 15$ & $s 16$ & $s 17$ & $s 18$ & $s 19$ & $s 20$ \\
& ocurrencias & 0 & 1 & 9 & 40 & 31 & 17 & 65 & 63 \\
& por millón & 0.00 & 0.78 & 3.16 & 9.23 & 9.47 & 7.76 & 6.68 & 3.11 \\
\hline \multirow{3}{*}{ conselhar } & sección & $s 13$ & $s 14$ & $s 15$ & $s 16$ & $s 17$ & $s 18$ & $s 19$ & $s 20$ \\
& ocurrencias & 17 & 7 & 21 & 17 & 0 & 0 & 0 & 0 \\
& por millón & 30.85 & 5.44 & 7.38 & 3.92 & 0.00 & 0.00 & 0.00 & 0.00 \\
\hline
\end{tabular}

Tabla 6. Aconselhar y conselhar en el CPMD

Con respecto al CA, sucede lo mismo. En el VIS (s. XIV) se registra la forma prefijada, denotando el sentido de 'orientar, dar o recibir consejo':

E cada vesitaçio $<\mathrm{n}>$ destas por conssilios notorios de los medicos discretos aujdos. vt bon $<$ us $>$ pastor ssapiens a con $<\mathrm{n}>$ oçer \& aconsejar a las ssus ouejas el bie $<\mathrm{n}>\mathrm{q}<\mathrm{ue}>$ an de fazer por auer el galardon ssobredicho.

A su vez, en el CORDE, para los siglos XIII y XIV, al lado de la forma con prefijo ocurre la forma no prefijada (ALX - s. XIII), una y otra con el mismo sentido y, como tal, comportándose como formas corradicales equivalentes:

25. Varela Barreiro (dir.) (en línea). 
Pero segunt mi seso quiérote consejar: con dueña más de preçio nunca podriés casar; demás en paz bien era tan grant tierra ganar, que siempre non oviésemos en guerra a durar.

Una vez más los registros del CEMD confirman la fluctuación corradical, perceptible en los cómputos que muestra la tabla a continuación, con la predominancia de la variante no prefijada en el medievo y la ascensión de la prefijada a partir del s. XVI, de modo muy semejante a lo que pasó con tales formas en el GP.

\begin{tabular}{llccccccccc}
\hline \multicolumn{1}{c}{ CEMD - https://www.corpusdelespanol.org/ } \\
\hline \multirow{3}{*}{ aconsejar } & sección & $s 13$ & $s 14$ & $s 15$ & $s 16$ & $s 17$ & $s 18$ & $s 19$ & $s 20$ \\
& ocurrencias & 22 & 11 & 14 & 120 & 87 & 42 & 113 & 25 \\
& por millón & 3.28 & 4.12 & 1.72 & 7.04 & 7.05 & 4.28 & 5.86 & 1.10 \\
\hline \multirow{3}{*}{ consejar } & sección & $s 13$ & $s 14$ & $s 15$ & $s 16$ & $s 17$ & $s 18$ & $s 19$ & $s 20$ \\
& ocurrencias & 72 & 77 & 57 & 8 & 0 & 2 & 3 & 0 \\
& por millón & 10.72 & 28.84 & 6.98 & 0.47 & 0.00 & 0.20 & 0.16 & 0.00 \\
\hline
\end{tabular}

Tabla 7. Aconsejar y consejar en el CEMD

Para ambos sistemas lingüísticos, el cuadro de oscilación entre las voces corradicales no se ha mantenido con el paso del tiempo, visto que ocurrió la selección y el predominio de la forma prefijada sobre la no prefijada, prevaleciendo esta como única opción válida en el léxico común castellano - decayendo la corradical a un estatus de obsolescencia (rotulada por el DLE/RAE como forma desusada) — y perviviendo en el gallego y en el portugués contemporáneos, pero como variante de muy poca representatividad si comparada con su corradical (al menos en el portugués ${ }^{26}$ ). Otros ejemplos que pasaron por el mismo proceso diacrónico de arcaización o pérdida de representatividad cuantitativa de la forma no prefijada en el castellano son acabdelar - cabdelar, acoitar - coitar, acompañar - compañar, acostumbrado - costumbrado, acostumbrar - costumbrar, airado irado, airar irar, apresurado presurado, arrebatar - rebatar, arredrar - redrar, aseguramiento seguramiento, atormentar tormentar, enagenar - agenar, avergonçado - vergonçado, enfermedad - fermedad, arrepentir - repentir, arrepentido - repentido. Lo mismo ocurrió, en el GP, con los pares acostumar costumar, agradecer gradecer, ajuntamento juntamento, ajuramentar juramentar, amercear - mercear, ameaçar - meaçar, apenhoramento - penhoramento, apoderar poderar, apodrecer - podrecer, aproveitar - proveitar, anogado - uogado.

26. El Dicionario da Real Academia Galega presenta la forma consellar y la remite a aconsellar, sin indicación de que ya no sea frecuente o que presente alguna marca de uso. 


\subsubsection{Equivalencia semántica plena con prevalencia de la forma no prefijada}

De la misma manera que la variante no prefijada de un par fluctuante equivalente podría convertirse a posteriori en una forma desusada, podría darse lo contrario, con la ascensión de la variante no prefijada a un estatus de forma privilegiada o única en periodos posteriores al medieval, como el contemporáneo. Es lo que se ejemplifica en los datos en (4), que muestran la alternancia entre las voces sinonímicas devedar vedar ('prohibir, impedir, privar, vetar'), siendo los dos primeros fragmentos para el GP y los dos últimos para el CA:

(4) devedar ${ }^{27}-$ vedar $^{28}$

[...] assy come quãdo os escomũgã ou os deuedam nô agardando a forma q(ue) he estabeleçuda ena Santa Jg(re)ia. (PP).

E sse for $\mathrm{b}(\mathrm{is})$ po aq(ue)l $\mathrm{q}(\mathrm{ue})$ vedarẽ do offizio nô deue $\operatorname{diz}(\mathrm{er})$ as oras côselheyram(ẽ) $\mathrm{t}(\mathrm{e})$ como ante, nẽ (con)sagrar nẽ côfirmar nẽ faz(er) ordees [...]. (PP).

Si el mio bue $<\mathrm{n}>$ maestro; no $<\mathrm{n}>$ melo deuedar. / Dexare Heuropa; yre passar la mar. (ALX).

Et los fieles con el sennor deuen vedar que ninguno de las partes non lis digan nulla ren a los combatedores. (Fuero de Tudela, s. XIII - CORDE)

Respecto al GP, tanto el DDGM como el CPMD solo recogen la forma sin prefijo (desde los primeros siglos de documentación escrita en ese sistema lingüístico), lo que se muestra en la tabla 8. A un panorama semejante conduce el TMILG, aunque en sus registros las formas sin prefijo tengan muy pocas ocurrencias, todas incrustadas en el s. XIII. No obstante, tanto el DVPM como las búsquedas en los documentos textuales que basaron este estudio han conducido a la identificación coetánea de las formas devedar - deuedar, incluso bajo la manifestación participial.

\begin{tabular}{llcccccccc}
\hline \multicolumn{10}{c}{ CPMD - https://www.corpusdoportugues.org/ } \\
\hline \multirow{4}{*}{ vedar } & sección & $s 13$ & $s 14$ & $s 15$ & $s 16$ & $s 17$ & $s 18$ & $s 19$ & $s 20$ \\
& ocurrencias & 1 & 22 & 3 & 5 & 13 & 6 & 10 & 10 \\
& por millón & 1.81 & 17.09 & 1.05 & 1.15 & 3.97 & 2.74 & 1.03 & 0.49 \\
\hline
\end{tabular}

Tabla 8. Vedar en el CPMD

27. Probablemente del lat. tard. ${ }^{*}$ DeVetare $<$ DE- + -VETARE.

28. Del lat. VETĀRE. 
En el CORDE, para varios textos de los siglos XIII y XIV, en paralelo a la forma con prefijo, se registra la forma no prefijada, denotando ambas el mismo sentido y, por tal razón, comportándose como formas corradicales fluctuantes. El CCMD presenta para el CA sólo una ocurrencia de devedar, en claro contraste cualitativo con su corradical, este con absoluta representatividad en el periodo:

\begin{tabular}{llccccccccc}
\hline \multicolumn{1}{c}{ CEMD - https://www.corpusdelespanol.org/ } & & & \\
\hline \multirow{3}{*}{ vedar } & sección & $s 13$ & $s 14$ & $s 15$ & $s 16$ & $s 17$ & $s 18$ & $s 19$ & $s 20$ \\
& ocurrencias & 120 & 18 & 89 & 32 & 5 & 5 & 10 & 1 \\
& por millón & 17.87 & 6.74 & 10.90 & 1.88 & 0.40 & 0.51 & 0.52 & 0.04 \\
\hline \multirow{3}{*}{ devedar } & sección & $s 13$ & $s 14$ & $s 15$ & $s 16$ & $s 17$ & $s 18$ & $s 19$ & $s 20$ \\
& ocurrencias & 0 & 0 & 1 & 0 & 0 & 0 & 0 & 0 \\
& por millón & 0.00 & 0.00 & 0.12 & 0.00 & 0.00 & 0.00 & 0.00 & 0.00 \\
\hline
\end{tabular}

Tabla 9. Vedar y devedar en el CEMD

Corominas \& Pascual (1991) también presentan las formas del par en variación, indicando la prefijada como forma antigua (arcaísmo). Con la evolución del GP y del castellano, la fluctuación no se ha mantenido, visto que se ha dejado de usar la forma devedar (ni siquiera registrada en el DLE/RAE) y pasaron a ser las formas exclusivas los verbos sin prefijo (vetar/vedar), denotando los mismos sentidos. Algo semejante sobrevino a los pares corradicales castellanos acuidar cuidar, aguisar guisar, aleuantamiento - leuantamiento, alimpiar - limpiar, alimpiado - limpiado, aprovechoso - provechoso, aquedar - quedar, asemejado - semejado, aseñorear señorear, asosegar - sosegar, asosegado - sosegado, asosiego sosiego, conombrar nombrar, defalimiento - falimiento, detardar - tardar. Y una situación análoga se constata en los pares gallego-portugueses acuydar - cuidar, afortificado - fortificado, alevantamento - levantamento, amergulhar - mergulhar, apacificado - pacificado, aprover - prover, concambiar - cambiar, concambio cambio, ensenhor(e)ar senhor(e)ar, acorrigir corrigir, detardança - tardança, deuedado - uedado, devedar - vedar, ensujar - sujar.

Se trata, por lo tanto, de un cambio en la lengua (precedido, como de regla, por una variación) que deshizo la coexistencia entre las formas sinonímicas, con la prevalencia de la corradical sin prefijo.

\subsubsection{Equivalencia semántica plena con obsolescencia de ambas formas}

Este subgrupo contempla corradicales equivalentes que con el paso del tiempo cayeron en obsolescencia en la lengua. En esta aproximación al tema no se encontraron 
en el corpus documental analizado o en las bases de datos de apoyo ejemplos de vocablos corradicales sinonímicos en el gallego-portugués y castellano medievales que sufrieron los mismos efectos de obsolescencia en época moderna o contemporánea. Quizás fuera un ejemplo alimpamentolalimpiamiento - limpamentollimpiamiento, pero, como se identificó un único uso en el periodo arcaico para la forma gallego-portuguesa no prefijada (a diferencia del CA, en el que hay innumerables usos de las dos voces), no consideramos adecuado utilizar tal ejemplo. Además, aunque considerando ambas formas en franco desuso en el portugués moderno (incluso en internet es extremadamente raro encontrar algún ejemplo), diccionarios como el Houaiss \& Villar (2009) traen alimpamento - limpamento sin ninguna observación de que ya sean formas desusadas. Por esas razones, se presentarán pares distintos para cada uno de los sistemas lingüísticos enfocados.

Para el GP, el tipo de fluctuación antedicho, con la obsolescencia moderna (o contemporánea) de todo el par, se encuentra en agracir - gracir (ejemplificado a continuación), presentes en la obra Flos Sanctorum, del siglo XIV — formas que tienen ambas el sentido de 'agradecer, mostrar gratitud'-. Igual fluctuación se aprecia, por ejemplo, en los corradicales arrecudir - recudir, amerger merger, demessar - messar.

(5) agracir $^{29}-$ gracir $^{30}$

[...] muyto o devia agracir a nostro senhor e amá-lo [...].

[...] começou a confiar de si meesmo e nô gracia a Deus.

Se detecta un ejemplo de ese tipo de fluctuación para el CA en fragmentos de textos del siglo XIII que contienen las formas abeurar - beurar, incluso en un mismo documento (LFU, GGE), denotando una y otra el sentido de 'beber, sorber':

(6) abeurar $^{31}-$ beurar $^{32}$

[...] p-lego al pozo o abeurauan to-doslos de la cibdat.

[...] ala manceba que tu dixi-eres dam del agua $\&$ beure. e ella dixiere bef tu $\&$ tus cam-ellos abeura. essa estaulit. pora to sieruo ysaac..

29. Del GP A- + -GRAÇA < lat. GratĬA, AE.

30. Del GP GRAÇA < lat. GRATǏA, AE.

31. Del catal. ABEURAR < catal. A- + BEURE, 'beber' < lat. BĬBĔRE.

32. Del catal. BeURe, 'beber' < lat. BĬBĔRE. 
Tanto abeurar como beurar cayeron en desuso con la evolución de la lengua, probablemente ya a fines del siglo XV o a comienzos del siglo siguiente. Una situación análoga se aplica a los pares castellanos acomendar comendar, acomendado comendado, aguisado - guisado (adj.), alimpiamiento - limpiamiento, cuyas formas ya no se usan más en su léxico común.

\subsection{Diferenciación semántica plena}

Además de la fluctuación con equivalencia semántica total entre las formas en el periodo medieval, hay un segundo macrogrupo de ocurrencias, en el que se constata una clara diferenciación semántica entre las formas del par corradical, que puede o no tener su génesis en flujos metafóricos o metonímicos. Se presenta a continuación un par léxico en que se activa ese tipo de fluctuación (los dos primeros ejemplos son del GP; los dos últimos, del CA):

(7) $a s(s) a c a r^{33}-s a c a r^{34}$

Outrosi a defensom se perderia muy toste se o uso das armas non ouvessem, e porem asacarom os antiguos joguos de taes maneiras per que se pudesse recrear [...]. (LM).

[...] el mijsmo me quiso sacar os ollos da cabeça [...]. (Crónica Troyana - s. XIV).

La quinta es por asacar falso testimonio a otro por mal que le quiere. E esto es grand pecado e grand falsedat, e por eso es llamado falso testimonio [...]. (Castigos e documentos para bien vivir ordenados por el rey Sancho IV - s. XIII - CORDE)

Et esto, cuydamos que plaze a Díos, quar a Díus plogo en el día del sábado, ço es la fiesta, goarescer el emfermo et sacar del pozo el buey o el asno [...]. (Vidal Mayor - s. XIII - CORDE).

A partir de los ejemplos, no se nota un cuadro de sinonimia entre las formas corradicales en cuestión, sino una clara diferenciación semántica: mientras asacar denota 'inventar', sacar significa 'quitar, extraer, retirar, arrancar ${ }^{35}$. Los corpus traen innumerables casos de uso de los vocablos, pero cada uno con su respectiva red polisémica,

33. Del GP/CA A- + -SACAR < quizás del gót. sakan, 'pleitear'.

34. Quizás del gót. SAKAn, 'pleitear'.

35. Estos dos grupos de matices semánticos diferenciados para cada una de las formas corradicales también se dejan entrever en el vocabulario del castellano medieval de Cejador (2005), aunque de manera más lacónica. 
no pareciendo darse una confluencia entre ellos. Así, para el GP, según el DVPM, la forma prefijada denota 'atribuir', 'combinar', 'recuperar', mientras que la voz sin prefijo significa 'extraer, retirar' o 'mostrar, exhibir'. Las tablas a continuación, generadas respectivamente en el CPMD y en el CEMD, traen un panorama cuantitativo respecto al uso de los corradicales, con una clara indicación de una mayor vitalidad y pervivencia para la forma sin prefijo:

\begin{tabular}{llccccccccc}
\hline \multicolumn{1}{c}{ CPMD - https://www.corpusdoportugues.org/ } & & & \\
\hline \multirow{3}{*}{ assacar } & sección & $s 13$ & $s 14$ & $s 15$ & $s 16$ & $s 17$ & $s 18$ & $s 19$ & s20 \\
& ocurrencias & 1 & 0 & 1 & 4 & 2 & 4 & 1 & 1 \\
& por millón & 1.81 & 0.00 & 0.35 & 0.92 & 0.61 & 1.83 & 0.10 & 0.05 \\
\hline \multirow{3}{*}{ sacar } & sección & $s 13$ & $s 14$ & $s 15$ & $s 16$ & $s 17$ & $s 18$ & $s 19$ & $s 20$ \\
& ocurrencias & 39 & 91 & 19 & 3 & 6 & 2 & 20 & 57 \\
& por millón & 70.78 & 70.67 & 6.68 & 0.69 & 1.83 & 0.91 & 2.05 & 2.81 \\
\hline
\end{tabular}

Tabla 10. Assacar y sacar en el CPMD

\begin{tabular}{|c|c|c|c|c|c|c|c|c|c|}
\hline \multicolumn{10}{|c|}{ CEMD - https://www.corpusdelespanol.org/ } \\
\hline \multirow{3}{*}{ asacar } & sección & s13 & $s 14$ & $s 15$ & $s 16$ & s17 & s18 & s19 & s20 \\
\hline & ocurrencias & 26 & 3 & 1 & 1 & 0 & 0 & 0 & 0 \\
\hline & por millón & 3.87 & 1.12 & 0.12 & 0.06 & 0.00 & 0.00 & 0.00 & 0.00 \\
\hline \multirow{3}{*}{ sacar } & sección & s13 & $s 14$ & $s 15$ & $s 16$ & s17 & s18 & s19 & s20 \\
\hline & ocurrencias & 886 & 269 & 909 & 2097 & 1132 & 1001 & 1527 & 1101 \\
\hline & por millón & 131.93 & 100.77 & 111.38 & 123.10 & 91.67 & 101.97 & 79.13 & 48.24 \\
\hline
\end{tabular}

Tabla 11. Asacar y sacar en el CEMD

Esas dos formas corradicales siguen en uso en las lenguas, cada una con su especialización semántica, aunque con la arcaización de algunos sentidos o la generación de innovaciones: asacar actualmente denota en portugués 'imputar calumniosamente, atribuir sin fundamento' (Houaiss \& Villar 2009). Otros ejemplos para el GP serían enderençar - aderençar - derençar, encoutar coutar. Lo mismo ocurre con los pares encobrir cobrir y encubierto cubierto en el castellano medieval.

\subsection{Equivalencia y distinción semánticas parciales}

El tercer grupo de fluctuación entre corradicales con y sin prefijo se encuentra en una situación intermedia, ni de equivalencia plena ni de distinción total, sino de 
confluencia parcial. En otras palabras, las variantes vehiculan sentidos comunes, pero también poseen sentidos diferenciados, desde los primordios de las lenguas hasta hoy. Hay dos posibilidades: la forma prefijada es la más plurisignificativa (2.3.1.) y la forma no prefijada es la más plurisignificativa (2.3.2.).

\subsubsection{La forma prefijada es la más plurisignificativa}

(8) as (s)entar ${ }^{36}-\operatorname{sentar}^{37}$

Varios documentos de los siglos XIII-XIV, presentes tanto en el corpus documental analizado como en el CORDE, registran los verbos as(s)entar - sentar con sentidos parcialmente coincidentes: la forma prefijada podría denotar 1) 'establecer, erigir, fundar'; 2) 'poner o colocar algo de modo que permanezca firme e estable'; 3) 'registrar, poner por escrito'; 4) 'sentar(-se), tomar asiento'; mientras la forma sin prefijo sólo denotaba este último sentido, como se puede observar en los ejemplos a continuación:

Njnguno non puede assentar molinos en los ríos ni en las agoas que corren por los términos aillenos [...]. (Vidal Mayor - s. XIII; sentido 1).

[...] \& quando la oracion ouiere acabada; deue el mismo assentar la primera piedra. \& poner sobrella una cruz. (PP - s. XIV; sentido 2).

[...] djos' padre al c'ielo te fiz'o pujar / con $<$ e>l te fiz'o asentar com $<\mathrm{m}>\mathrm{o}$ a madre / s'en -ora oy al pecador ca tu fijo el s'aluador / por el desc'endio del c'ielo en ti morador / el q<ue> paris'te $s^{\prime}<$ an $>$ ta flor por nos' nac'io. (Vidal Mayor - s. XIII; sentido 4).

Et dichas aquestas cosas, casi doliendose, tornose a sentar en su lugar (Historia troyana - s. XIV; sentido 4).

Situación análoga atañe al GP medieval: assentar, según los datos del corpus textual estudiado y las informaciones del DVPM, podría vehicular al menos cuatro sentidos distintos - (1) 'sentar(-se), tomar asiento'; (2) 'atribuir posesión de bienes a uno'; (3) 'edificar'; (4) 'descansar, reposar, acostarse'- frente a un único para su corradical destituido de prefijo ('sentar(-se), tomar asiento'):

[...] e fecta a horacó assemtaran-sse. (VSMA; sentido 1).

36. Del CA/GP A- + -SENTAR < lat. *SEDENTĀRE, de SEDENS, -ENTIS.

37. Del lat. *SEDENTĀRe, de SEDEns, -entis. 
Se o alcayde mandar asseentar alguen en sa demãda ou en boa d(e) seu (con)tendor [...]. (FR; sentido 2).

E, quando foy aly onde fora pobrada a cidade de Talca, pareceulhe que nom estava em boo logar poboada e andou buscando logar em que a aseentasse de novo. (CGE; sentido 3).

[...] conhescer as cousas que os demais dos porcos fazem quando se querem assentar. (LM; sentido 4).

[...] os angeos Santa Maria fillaron / e ena çima do altar a sentaron [...]. (CSM; sentido 1).

Los datos del CPMD y del CEMD corroboran la fluctuación existente entre as $(s)$ entar y sentar en diversos periodos de la lengua, habiendo, no obstante, oscilaciones en sus respectivos cómputos de uso, ya que hay siglos en que una se sobrepone a la otra. Además, se nota que, en todo el periodo medieval, la forma prefijada era la más abundante, situación que cambia en los siglos subsecuentes (sentar pasa a presentar mayor frecuencia en el castellano desde el s. XIX y en portugués desde dos siglos antes):

\begin{tabular}{llccccccccc}
\hline \multicolumn{1}{c}{ CPMD - https://www.corpusdoportugues.org/ } & & & \\
\hline \multirow{3}{*}{ assentar } & sección & s13 & s14 & s15 & s16 & s17 & s18 & s19 & s20 \\
& ocurrencias & 0 & 3 & 34 & 213 & 82 & 122 & 74 & 126 \\
& por millón & 0.00 & 2.33 & 11.95 & 49.16 & 25.06 & 55.72 & 7.60 & 6.22 \\
\hline \multirow{3}{*}{ sentar } & sección & $s 13$ & $s 14$ & $s 15$ & $s 16$ & $s 17$ & $s 18$ & $s 19$ & s20 \\
& ocurrencias & 1 & 2 & 1 & 10 & 5 & 5 & 133 & 240 \\
& por millón & 1.81 & 1.55 & 0.35 & 2.31 & 1.53 & 2.28 & 13.66 & 11.84 \\
\hline
\end{tabular}

Tabla 12. Assentar y sentar en el CPMD

\begin{tabular}{|c|c|c|c|c|c|c|c|c|c|}
\hline \multicolumn{10}{|c|}{ CEMD - https://www.corpusdelespanol.org/ } \\
\hline \multirow{3}{*}{ asentar } & sección & s13 & s14 & s15 & s16 & s17 & s18 & s19 & s20 \\
\hline & ocurrencias & 31 & 37 & 185 & 229 & 103 & 47 & 86 & 23 \\
\hline & por millón & 4.62 & 13.86 & 22.67 & 13.44 & 8.34 & 4.79 & 4.46 & 1.01 \\
\hline \multirow{3}{*}{ sentar } & sección & s13 & s14 & $s 15$ & s16 & s17 & s18 & s19 & $s 20$ \\
\hline & ocurrencias & 3 & 8 & 39 & 197 & 108 & 76 & 197 & 133 \\
\hline & por millón & 0.45 & 3.00 & 4.78 & 11.56 & 8.75 & 7.74 & 10.21 & 5.83 \\
\hline
\end{tabular}

Tabla 13. Asentar y sentar en el CEMD 


\subsubsection{La forma no prefijada es la más plurisignificativa}

(9) acometer $^{38}-$ cometer $^{39}$

En el GP medieval, igual que en el CA, se daba la fluctuación entre las formas acometer - cometer, pero siendo la forma sin prefijo más polisémica que su corradical. En la primera lengua, la voz prefijada denotaba (1) 'atacar, embestir, asaltar'; la no prefijada, a su vez, además de ese primer sentido, también vehiculaba las acepciones de (2) 'realizar, practicar, emprender', (3) 'confiar, conceder, encargar', (4) 'jugar, practicar' o (5) 'obligar por compromiso':

[...] e os mouros nó os ousavam acometer por a gram fortelleza deste rey dó Afonsso. (CGE; sentido 1).

Fazede vosso combatimento o mais aficado que poderdes, ca o conde dom Froiaz Vermuiz de tal feito é que nom comete nenguem se lhe tem as costas voltas, e de nosso emmigo que ele é hoje, será nosso amigo.(NLL; sentido 1).

E pois razon a tan descomunal / fostes filhar, e que tan pouco val, / pesar-mi-á en, se vos pois a ben sal / ante o Diaboo, a que obedecestes. / E ben vej' ora que trobar vos fal, / pois vós tan louca razon cometestes. (CEM13; sentido 2).

Estas som as riquezas $\mathrm{p}(\mathrm{er})$ as $\mathrm{q}(\mathrm{ua})$ es me o diaboo por os me(os) pecad(os) e maldades tragia emganada, por em as dou e cometo aa tua santidade e arbitrio. (VSMA; sentido 3).

E ella cometya muitas vezes baralha co $\sim$ todas sas vizinhas e bevia do vinho mais que lhe (con)pria. (VSMA; sentido 4).

El rey dố Pedro namorousse de dona Johana de Castro e cometeua de casamẽto, asalvãdo que dona Branca de Barbã nô era sua molher. (CAXP - Crónica de Afonso X - s. XIv DVPM; sentido 5).

Tanto los testimonios textuales investigados como el DVPM y el CIPM corroboran la situación de una mayor polisemia y frecuencia de cometer sobre acometer, forma última esta que ni siquiera ocurre en el DDGM y en el TMILG, en contraposición con su corradical sin prefijo, que se manifiesta profusamente en estos dos últimos bancos de datos y en todos los demás consultados.

38. Del PA/CA A- + -COMETER < lat. COMMǏTTĚRE < CUM- + -MITTĚRE.

39. Del lat. COMMIITTĚRE < CUM- + -MITTĚRE. 
Para el CA, de los ejemplos encontrados en el conjunto documental analizado, así como de los del CORDE, se deduce que el vocablo prefijado denotaba las nociones de 1) 'atacar, embestir con ímpetu, arremeter'; 2) 'realizar, ejecutar, emprender, hacer'; 3) 'proponer, sugerir'; a su vez, la forma sin prefijo, aparte de vehicular tales sentidos, también parecía indicar otros, como 4) 'prometer, comprometer, obligar por compromiso' y 5) 'rendir, exponer, manifestar, afianzar'. Esta red polisémica del par léxico se refleja en los ejemplos siguientes ${ }^{40}$ :

Et en este capit $<\mathrm{u}>$ lo paramye $<\mathrm{n}>$ tes al bien. \& al mal $\mathrm{q}<\mathrm{ue}>$ accaece alos Reyes. \& a sus enemigos. segu $<\mathrm{n}>\mathrm{t}$ sus uillas. \& sus $\mathrm{t}<\mathrm{ier}>$ ras por acometer se los unos alos $\mathrm{ot}<\mathrm{r}><<<\mathrm{0}>>\mathrm{s}$ en ellas. (CRZ; sentido 1).

E los alcaldes preguntaron al cavallero por qué se atreviera de acometer tan gran cosa como aquella en quebrantar las prisiones del señorío por que no se cumpliesse la justicia. (Libro del cavallero Cifar - s. XIV - CORDE; sentido 2)

[...] \& luego enbio a acometer al Rey don sancho que casaria con su fija la jnfanta dońa ysabel \& que serie su amjgo. (Crónica de Sancho IV-s. XIv - CORDE; sentido 3).

[...] començó a bollir e cometer las yentes de las otras tierras, e guerrearlas e rebolverlas por meterlas so el su señorío. (GEE; sentido 1).

La .3a. cosa en cometer omne grandes fechos $\&$ ponerse a grandes auenturas. (Castigos s. XIII - CORDE; sentido 2)

[...] rruegouos que me non fabledes en esta rrazon, ca amj vienen cometer con muchos casamientos buenos en que escoia vno qual me pagare. (Tratado contra hadas - s. XIV CORDE; sentido 3).

Los alcaldes deuen fazer tres uezes en el anno ayuntamiento de los omes buenos, asy como cabildo, a ordenar sus cosas e a cometer paz entre sy. (Privilegio dado por el rey don Enrique - s. XIV - CORDE; sentido 4).

40. Son frecuentes en el CORDE los contextos en los que en un mismo fragmento textual (muchas veces en un mismo párrafo) se alternan las formas sinonímicas con y sin prefijo. Son ejemplos de ese hecho la oscilación de acometer - cometer en el Libro del cavallero Cifar o en la Crónica de veinte Reyes (ambos del s. XIV), respectivamente: "E quando el esto oso acometer a ihesu xpisto que era su señor non era maraujlla de cometer alos santos que eran sus siervos [... ]."; "Don lorenço suares quando lo vio tornar dixo al Rey vedes commo torna alos otros moros vuestro garçi peres quando vio que los moros non le querien acometer \& agora va el cometer a ellos.". 
Et quando supieron que venja Jullio çesar enbiaronle cometer sus pletesias que non contendiese conellos \& los dexase estar commo estauan \& que ellos le darian pasada \& non le pornjan enbargo njnguno. (Crónica de 1344 - s. xIV - CORDE; sentido 5).

Este último tipo de variación entre formas corradicales con y sin prefijo - que también actúa en otros pares del castellano y del gallego-portugués- es la que señala una fluctuación parcial entre ellas, pero en la que el componente más plurisignificativo es la forma no prefijada.

En todos los ejemplos anteriores de fluctuación con equivalencia/distinción parciales, una de las formas del par o incluso ambas han permanecido en uso en la lengua, lo que ha pasado, por ejemplo, con cometer y acometer (cf. tabla 14).

\begin{tabular}{llccccccccc}
\hline \multicolumn{10}{c}{ CPMD - https://www.corpusdoportugues.org/ } \\
\hline \multirow{3}{*}{ cometer } & sección & $s 13$ & $s 14$ & $s 15$ & $s 16$ & $s 17$ & $s 18$ & $s 19$ & $s 20$ \\
& ocurrencias & 11 & 31 & 129 & 419 & 52 & 13 & 122 & 172 \\
& por millón & 19.96 & 24.07 & 45.35 & 96.70 & 15.89 & 5.94 & 12.53 & 8.49 \\
\hline \multirow{3}{*}{ acometer } & sección & $s 13$ & $s 14$ & $s 15$ & $s 16$ & $s 17$ & $s 18$ & $s 19$ & $s 20$ \\
& ocurrencias & 0 & 1 & 1 & 22 & 28 & 22 & 24 & 10 \\
& por millón & 0.00 & 0.78 & 0.35 & 5.08 & 8.56 & 10.05 & 2.46 & 0.49 \\
\hline
\end{tabular}

Tabla 14. Cometer y acometer en el CPMD

\section{Consideraciones generales sobre el fenómeno}

La fluctuación prefijal es un fenómeno de presencia constante en la ruta histórica del gallego-portugués y del castellano, pujante mayormente en el medievo. Ese tipo de variación impresiona tanto por su vitalidad en la lengua medieval (y, en menor medida, en la época moderna y contemporánea) como por su complejidad, instaurada en variopintas corrientes de variación y cambio, y es objeto de enorme controversia e interés porque desafía las diferentes teorías lingüísticas.

No se trata de una innovación de las lenguas neolatinas, sino del latín mismo, lengua que se valía recurrentemente de la afijación prefijal como un procedimiento substancial para la formación y el incremento de su depósito léxico (cf. Dinu 2012) y de suma importancia en la configuración de las innumerables familias léxicas ${ }^{41}$. Se

41. Son muy numerosas las familias léxicas derivativas presentes en la lengua latina y formadas mediante la adjunción prefijal. Algunos ejemplos, que comprueban la vitalidad y la fuerza de ese mecanismo en la lexicogénesis latina, son los siguientes: sum, es, esse, fǖ $\rightarrow$ absum, dèsum, insum, intērsum, prōsum, subsum, supērsum; mittō, -is, ěre, mīsī, missum $\rightarrow$ admittō, committō, dēmittō,

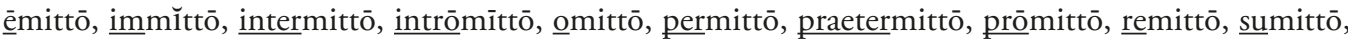


puede admitir que, debido a la irrefutable primacía del estrato latino en la constitución del léxico romance - en cuanto a los constituyentes y también a los mecanismos genolexicales-, la comprensión de muchos fenómenos de la formación de palabras de los idiomas neolatinos depende de la comprensión de los mecanismos léxico-morfológicos de su matriz (Mattos e Silva 2008a; Rio-Torto 1998; Viaro 2010). En otras palabras, el modus operandi de la lexicogénesis romance se inspira en el modus operandi de la lexicogénesis latina y, por consiguiente, lo refleja.

Es lo que se observa en la prefijación y en sus modos de operación en las lenguas ibéricas, cuyos vocablos prefijados en circulación se originan (muchos de ellos) del latín culto, en el que era particularmente activa la adjunción prefijal. La importancia a la lexicogénesis romance va más allá del hecho de ser un recurso propiciador de un copioso rol de voces heredadas, pues, además de ello, le ofrece un conjunto imprescindible de modelos y esquemas genolexicales (Pena 1995), un vehículo potente para el enriquecimiento del vocabulario romance en sincronías pretéritas y hodiernas. De ahí que se puede decir con justicia que el latín "[...] offered Romance languages a rich lexical inventory and a model for their own creativity" (Dinu 2012: 134).

El fenómeno de la coexistencia de formas sinonímicas con y sin prefijo ya se manifestaba en el latín, con la participación de los formativos $a(d)$-, co-, de-, $e(x)$ - e $i(n)$-. Romanelli (1964) enumera varios ejemplos de prefijos de sentido 'cero' o con vaciamiento de contenido semántico en la lengua latina (dealbo, deambulo, deargento, deauro, derelinquo, effercio, ementior, evincio, illuceo, imminuo, insono, inunguo), actuantes en formas derivadas semánticamente equivalentes a sus corradicales no prefijadas; lo mismo se observa en las listas de vocablos latinos (compleo, cognosco, irrideo, illustro, immito, inmmuto, impleo) de Segura Munguía (2000). Batllori / Pujol (2012) señalan que se nota en muchos vocablos del latín un proceso de desemantización general de los prefijos $a b$-, $a d$-, in- (locativo), que no aportan sentidos complementarios a los derivados ${ }^{42}$, como se observa en los ejemplos (10)-(14), extraídos de obras de César, Cicerón y Plinio, reproducidos en el estudio mencionado:

exercitum ducere / exercitum adducere, ambos verbos con el sentido de 'mandar, guiar un ejército, marchar a su frente';

eum sonitum aures hominum capere non possunt / auribus accipere, teniendo las formas capere y accipere idéntico significado, 'oír';

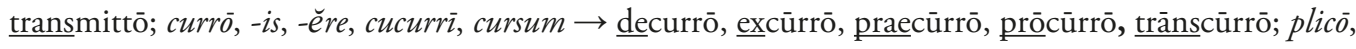

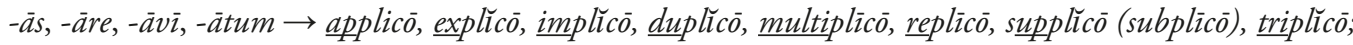
fèro, fers, ferre, tŭ $l i$, lätum $\rightarrow$ affero, aufero, circumféro, confero, defero, differo, effero, infero, offero, perfero, praefero, refero, suffero, superféro; pōnō, -is, -е̌re, posŭ $\bar{i}$, posìtum $\rightarrow$ antepōnō, compōnō, contrapōnō, depōnō, dispōnō, expōnō, impōnō, interpōnō, oppōnō, postpōnō, praepōnō, repōnō, superpōnō, suppōnō, trānspōnō, recompōnō, decompōnō.

42. O que funcionan como simples apoyos de refuerzo en verbos incoativos, como en accresco, adaresco, adaugesco, addisco, incalesco, incandesco, incanesco (Beltrán 1999 apud Batllori \& Pujol 2012). 
sequor / insequor, ambos con el significado de 'seguir'; colere / incolere, ambos con el significado de 'habitar'; cubare / incubare, ambos con el significado de 'acostarse'.

Si se atiende a la variación sinonímica de corradicales con y sin prefijo en el gallego, en el portugués y en el castellano, en sus sincronías medievales o en las contemporáneas, se comprueba con respecto al fenómeno que sus pautas morfolexicales son muy semejantes a las latinas, tanto en lo que se refiere a los prefijos involucrados (sobre todo ad-e in-), como en el tipo de formación a que se aplican (mayormente verbal).

La búsqueda profundizada sobre el tema revela que hay escasas reflexiones sistemáticas sobre ese tipo peculiar de variación —en coocurrencia o en concurrenciaen el latín o en sus descendientes, lo que no deja de ser intrigante, ya que es un proceso de gran amplitud en tales sistemas lingüísticos. Como problema complejo que es, tiene serias consecuencias en puntos canónicos centrales de la reflexión morfológica, como el propio concepto de morfema. Se trata de una cuestión que es en sí una gran interrogación y que conlleva una serie de cuestionamientos, como el que Šinková (2013) explicita con respecto a algunos corradicales parasintéticos en el español del siglo xIx: ¿Cuáles los motivos que llevaban a los hablantes a la creación de una nueva forma semánticamente idéntica a una corradical ya existente?

A su vez, en el gallego-portugués, a los ejemplos reproducidos en las secciones anteriores podrían añadirse muchos otros, como los pares léxicos acorreger - correger, emcardecer - cardecer, desronper - romper, enpuxar - puxar ${ }^{43}$. Los prefijos actuantes en tal cuadro de variación son $a-$, con-, de-, des-, en-, es-, re-y trans-, con predominio cuantitativo del primer formante (que figura en un $64 \%$ de los casos), seguido por en- (un $14 \%$ ) y de-(un 12,5\%). Una de las primeras reflexiones sobre la alternancia corradical en portugués se encuentra en la Grammatica da lingoagem portuguesa, de Fernão de Oliveira (1536, cap. XXXV), y documentada con hechos de lengua de su época:

\footnotetext{
Alghũas partes ou vozes temos na nossa língua as qes são parte porsi mas não significão cousa alghuã [...]. Hũa çerta maneira de diçóes mayormẽte verbos temos nos q pareçe juntos como apanhar: arranhar. açoutar. abertura: abastança. açerto: mas na verdade isto em muitas partes não he ajuntamento se não costume bẽ ameudado entre nos: posto que as vezes tambẽ he ajuntamento: como acorrer. apareçer. aconselhar. Porq as partes dos primeiros não se achão apartadas. e as destes derradeiros si: como correr. pareçer. conselhar.
}

En el castellano medieval actuaban en el fenómeno los prefijos $a-$, con-, dey en ${ }^{-44}$, siendo los más profusos $a-(82 \%)$, en $(9,5 \%)$ y de- $(6 \%)$. Varios autores

43. Ejemplos extraídos del estudio de Lopes (2013).

44. En el corpus textual castellano analizado no se observa la participación de los prefijos des-, es-, re- y trans-, pero se puede admitir que de hecho actuaban en pares corradicales fluctuantes, al menos 
traen informaciones sobre la fluctuación corradical en castellano, como Sánchez-Prieto Borja (1993), que la considera un rasgo característico de la lengua en su sincronía medieval, Salomonski (1944), que la interpreta como una forma de exhibición de recursos, o Sánchez González de Herrero (1992), que detecta en textos médicos castellanos medievales la existencia de varios derivados parasintéticos del esquema a...ecer y en...ecer que conviven con formas sin los respectivos prefijos, siendo (para) sinónimos, como blandecer, blanquecer, bermejecer, dormecer, flaquecer, magrecer, mollecer, negrecer, podrecer. Esta autora llega a la conclusión que las formas alternantes no presentan diferenciaciones de uso, de significado o de estilística, afirmando que:

[...] en los textos médicos del XIV y XV conviven aún un buen número de derivados verbales de una misma raíz (es muy frecuente que sean dos o tres, en ocasiones hasta cuatro o cinco) cuyos valores y funciones en la mayor parte de los casos no es posible diferenciar, puesto que se entremezclan de continuo. Esta variedad es especialmente notable en los derivados de adjetivales, donde encontramos, por ejemplo, sobre el adjetivo triste: atristar, contristar, contristecer, entristecer y tristecer, sobre blando: ablandar, ablandecer, emblandar, emblandecer y blandecer, de muelle: amollecer, enmollecer, remollecer y mollecer; con negro: anegrecer, denegrecer, ennegrecer o negrecer; de blanco: emblanquecer, blanquear y blanquecer, etc. (Sánchez González de Herrero 1992: 1318)

Según Sánchez Martín (2008), García Medall (1994) contabiliza, en un rol de 300 verbos prefijados en $a$-, más de 170 que no se oponen semánticamente a sus corradicales no prefijados. Pascual Rodríguez (1974: 128) afirma que "El castellano conoce y ha conocido la posibilidad de muchos dobletes entre formas que comienzan por $a$ - y formas que comienzan por $\varnothing$-, como (a)caecer, (a)matar, (a)sentar, (a) (r)ascar, (a)baxar, (a)limpiar, (a)mostrar, etc.". Romero Aguilera (2009: 720) presenta aserciones convergentes con las de los autores mencionados, detectando en un corpus del castellano medieval la forma borrecible en variación con aborrecible (ambas registradas en el s. Xv), señalando también que la presencia del corradical no prefijado puede explicarse "[...] por la frecuencia con la que en la lengua antigua, especialmente en zona aragonesa, se podía producir alternancia entre lexema con y sin prefijo, sobre todo en el caso del prefijo $a$-, sin que ello conllevara diferencia de significado léxico".

El gallego-portugués y el castellano comparten, con respecto al fenómeno en destaque, algunas líneas de actuación generales, que podrían funcionar como conclusiones del análisis de los datos documentales seleccionados: (i) la intensidad de

los dos primeros prefijos. Pharies (2013) lista innumerables ejemplos de alternancia léxica con es- (totalmente sinonímica, parcialmente sinonímica o semánticamente contrastante), sea en el castellano antiguo (esblandir - blandir, escalentar - calentar, esclarecer - clarecer, esbrindarse - brindar, escarmenar - carmenar, escomer - comer, espartir partir, esprestar prestar, estajar tajar), sea en el moderno (escomenzar - comenzar, esperecerse - perecer, estropezar - tropezar). 
la fluctuación prefijal es muy superior en el medievo que en la actualidad; (ii) la fluctuación incide mayormente en productos verbales, parasintéticos o no, ya que en ambas lenguas medievales la principal función lexicogenética de los prefijos era (y lo sigue siendo) actuar en la constitución de verbos; (ii) hay casos en los que la variación lexema prefijado - lexema no prefijado se observa en formas verbales y deverbales; (iii) hubo dificultades en encontrar pares corradicales de una misma clase de fluctuación en ambas lenguas; por eso no hay en este artículo la comparación entre un mismo par léxico corradical con y sin prefijo en todas las categorías; (iv) no se ha encontrado en el corpus documental o en las bases de datos de apoyo ejemplos de vocablos corradicales sinonímicos en el gallego-portugués y castellano medievales que sufrieron los mismos efectos de obsolescencia en la época moderna; (v) para las demás clases de fluctuación se hallaron pares corradicales comunes a las dos lenguas, lo que indicia, tal como en los casos anteriores, caminos paralelos/convergentes de comportamiento en el dominio estudiado; (vi) el análisis de los datos empíricos muestra que la equivalencia semántica plena con pervivencia de ambas formas hasta el presente es muy rara: (de)pendurar (GP), (a)costumbrar (CA), siendo más frecuente la marcación diastrática, diafásica y/o diatópica de una de las formas (cf. juntarlajuntar, iuntarlaiuntar); (vii) las situaciones más comunes implican diferenciación semántica plena (sacar vs. as(s)acar), equivalencia semántica plena inicial con prevalencia de la forma prefijada (aconselharlaconsejar) o de la forma no prefijada (vedar vs. devedar) y equivalencia/distinción semántica parciales, en la cual la forma prefijada (as(s)entar vs. sentar) o la forma no prefijada (cometer vs. acometer) es la más plurisignificativa. En las tres situaciones la fluctuación acaba por desintegrarse con el paso del tiempo.

En el presente, existen diferencias en algunos pares corradicales entre los verbos con y sin prefijo (o con prefijos diferentes) en relación con la naturaleza [ \pm abstracta] de sus argumentos, como observa Bosque (1976): agrandar forma sintagmas con objetos que denotan entidades [+concretas], mientras engrandecer afecta a objetos [+abstractos]. Además, la amplitud de los rasgos semánticos de cada uno de los prefijos puede tener una importancia fundamental en la pervivencia de una o de otra forma verbal ([ \pm prefijada]). Es lo que puede haber ocurrido en aquellos casos en coexistencia desde el periodo medieval, pero que asumieron con el paso del tiempo sentidos propios, con especializaciones, ampliaciones o restricciones semánticas, conectadas a procedimientos metonímicos o metafóricos (Rainer 2010) o a diferentes efectos de perspectivización (Castro da Silva 2015) ${ }^{45}$.

Llama la atención la fuerza de los prefijos direccionales $a(d)$ - y en- en el procesamiento de la fluctuación prefijal, presentes en 8 de cada 10 pares corradicales en el corpus textual analizado. Tanto el primero (inicialmente adlativo) como el segundo (inicialmente ilativo) eran muy productivos, convirtiéndose aún en el latín en unida-

45. Para algunos planteamientos sobre aspectos histórico-cognitivos involucrados en la adjunción prefijal en gallego-portugués, véase el estudio de Carvalho (2016). 
des plurisignificativas, con una pujante extensión de su tela semántica, en trayectorias paralelas que con cierta frecuencia se entrecruzan en latín y en romance (Álvarez Huerta 2016) —ambos formantes podían denotar 'desplazamiento, con inserción dentro de lo que denota la base léxica' (aprisionar, encarcelar), 'cambio de estado' (amansar, enviudar) o 'transferencia de posesión' (amarguear, encerar) (Rio-Torto 2004). Lo que puede haber ocurrido en los pares con y sin prefijo bajo fluctuación es que los matices semánticos diferenciadores aportados inicialmente por los prefijos $a(d)$ - o en-progresiva o tendencialmente se fuesen debilitando, llegando a un nivel de total desaparición, conllevando la sinonimia entre los corradicales. La asunción de una progresiva disminución en la carga semántica de los prefijos mencionados queda corroborada por el planteamiento de Álvarez Huerta (2016: 13), al señalar que, en el cambio del latín a los romances,

[...] 'l prefixu llatín se debilita, perdiendo parte del so significáu orixinariu local - los prefixos llatinos indicaben llugar en, dende, escontra, per onde -, y amenorga a la simple espresión de la dirección n’astractu, de valores metafóricos, de manera que namás perviven los significaos preverbiales de dirección ( $(a-, e n-)$, qu'espresen un cambéu d'estáu, y los de separtación, qu'espresen la salida d'un estáu (es-, des-) (cfr. Acedo Matellán 2006: 14). Esa desemantización del preverbiu pue comprobase en casos en qu'un verbu prefixáu llatín tien descendiente directu en romance.

Además de la proximidad de los sentidos de 'aproximación' y de 'inserción', estos sentidos ab initio distintivos de ad-y de in- también son codificables por conversión, mecanismo claramente competitivo con los de afijación (Rio-Torto 2004; Pereira 2016). Asimismo, confirman ese pensamiento Batllori \& Pujol (2012), pues afirman que en el siglo XIII había una fuerte convivencia entre formas corradicales sinonímicas con el prefijo a-y sin él (ajuntar / juntar, apremiar / premiar, alimpiar / limpiar, asentar / sentar), alternancia que va perdiendo fuerza a lo largo de la Edad Media, con la elección por parte de los hablantes de una de las formas, en detrimento de su correlativa.

De la observación del conjunto de ejemplos para el castellano y para el gallego-portugués, se concluye que esas lenguas (y quizás también el asturiano ${ }^{46}$ ) licenciaban los tres tipos posibles de fluctuación, con (i) la equivalencia semántica total entre los corradicales (perdurando en la lengua con marcas de uso, o que podrían deshacerse en el flujo histórico, con el solapamiento de una de las formas y la ascensión de su correlativa como única posibilidad), con (ii) la equivalencia semántica parcial entre

46. De los análisis y ejemplos que presenta Álvarez Huerta (2016), se puede pensar que los mismos tres tipos de fluctuación actúan en el asturiano en formas corradicales parasintéticas alternantes, con y sin el prefijo a-, como llimpiar allimpiar, afloxar floxar, amostiar mostiar, arroxar roxar, mostecer - amostecer, etc.; lo mismo en formas corradicales alternantes no parasintéticas (según la autora) como falagar - afalagar, xuntar - axuntar o fuxir - afuxir. 
los miembros del par morfolexical, o con (iii) la distinción semántica plena entre las formas (fuese o no a causa de interferencias metafóricas o metonímicas u otros fenómenos cognitivos, como la perspectivización).

De la triple posibilidad de fluctuación existente en los sistemas lingüísticos estudiados, emergen tres hipótesis explicativas para el fenómeno, que probablemente actúan conjuntamente en su evolución histórica: (i) si hay una equivalencia semántica entre los corradicales desde su surgimiento, ambos pueden permanecer a lo largo de los siglos, en una situación de variación constante (como en arremangar - remangar, para el castellano, o dependurado - pendurado, para el portugués); (ii) puede haber, en cambio, la obsolescencia de una de las formas de la pareja corradical inicialmente actuante (devedar vs. vedar) o su marcación diastrática, diafásica (ajuntar vs. juntar, aiuntar vs. iuntar) o diatópicamente; (iii) puede ocurrir, por fin, una tercera situación: a principio habrá una ligera diferenciación semántica que va evolucionando hacia un cuadro de plena diferenciación (cometer vs. acometer), con la permanencia de los corradicales o con la ascensión de uno de ellos, en detrimento del otro.

Con respecto a los flujos históricos de adjunción o supresión de prefijos en corradicales, en un cuadro de variación y cambio, con la fijación de una de las formas, es clarificador lo que señala Rio-Torto (1998b: 10), sobre tales procesos en el portugués, lo que, mutatis mutandis, podría aplicarse también al castellano:

Em relação a alguns verbos presentemente prefixados, é possível testemunhar ocorrências arcaicas privadas de operador prefixal, que posteriormente se lhes terá associado. São exemplos aduzidos por J. J. Nunes conselhar, contecer, devinhar, gradecer, actualmente configurados como aconselhar, acontecer, adivinhar, engrandecer. A estes podem ainda acrescentar-se mamentar, queecer, repender e tristecer, a que correspondem, no presente, amamentar, aquecer, arrepender, entristecer.

Mas também podem ser carreados exemplos de sentido inverso, ou seja, verbos que, no português medieval eram portadores de prefixo(s) e que, com a evolução da língua, se foram dele(s) despojando. Assim terá acontecido com afortalecer, ajuntar, alevantar, alimpar, empeiorar, empuxar, ençujar, equivalentes aos actuais fortalecer, juntar, levantar, limpar, piorar, puxar, sujar. Recorde-se, a propósito, que em Os Lusíadas ainda ocorrem os verbos achegar, alembrar, alevantar, alimpar, amostrar, arrecear, assoprar, esbombardear.

Como se nota, la fluctuación prefijal no se muestra como un fenómeno puntual o restricto, sino muy vivo en el trayecto constitutivo de las lenguas neolatinas, al menos en el portugués, en el castellano, en el asturiano y en el gallego. Claro está que no es una cuestión de simple explicación, pues mucho contraría el argumento de los efectos de la economía lingüística y se desvía abiertamente de la prototipicidad morfológica, basada en la biunivocidad, en el emparejamiento entre contenido y forma. Hipotéticamente hablando, lo que parece ocurrir, en gran parte de los casos, es una variación 
entre las dos formas correlativas en sincronías pretéritas de la lengua y, con el paso del tiempo (muchas veces ya a lo largo de la Edad Media, como señalan Batllori \& Pujol 2012), (i) la elección de una de las formas en detrimento de su corradical, que pasa a ser desusada, arcaica o infrecuente (Sánchez Martín 2008; García-Medall 1994) o poseedora de marcas de uso (diatópicas, diafásicas o diastráticas), aunque, para algunos de esos pares léxicos, la alternancia se consolide en la lengua, cristalizando variantes estables, como las expuestas en secciones anteriores de este ensayo; o (ii) la pervivencia de ambas formas, pero con sentidos más o menos divergentes.

Un punto importante de reflexión sobre el fenómeno consiste en comparar las formas vernáculas semánticamente equivalentes en variación con su respectivo étimo latino. Si este es prefijado (en el $26 \%$ de los casos para el gallego-portugués y en el $22 \%$ de los casos para el castellano), sería natural que el vocablo que de él se originó conservara el afijo. Así ocurre en algunos casos, pero no en todos. Para estos importaría saber cuáles fueron las motivaciones para la creación de un correlato sin el elemento prefijal (cf. partir, frente a departir), o sea, la emergencia de un corradical a través de la pérdida del prefijo.

Mutatis mutandis, si el étimo no es prefijado (en el $74 \%$ de los casos del gallego-portugués y en el $78 \%$ de los casos del castellano analizados), sería natural esperar que el lexema neolatino no contuviera el elemento prefijal ${ }^{47}$. Para formas en variación circunscritas al primer caso, sería de interés saber cuáles fueron las motivaciones para la creación de un correlato sin el elemento prefijal, o sea, la emergencia de un corradical a través de la pérdida del prefijo; ya para los pares del segundo caso, interesaría saber cuáles fueron los motivos para la aparición de un corradical con el añadido de un prefijo que no conlleva una carga semántica evidente.

Como la mayoría de las formas prefijadas en los pares fluctuantes surge en el vernáculo, la clave para la explicación de la fluctuación seguramente estaría en la indagación de la correlación de fuerzas (i) entre los prefijos en el latín, basada en un minucioso análisis (aún no disponible) de los pares sinonímicos fluctuantes en esa lengua, con sus motivaciones, sus trayectos morfolexicales y su comportamiento semántico y funcional; y (ii) entre los dos mecanismos diferentes de formación de verbos disponibles en la época medieval - la prefijación, presente en ajuntar, ajuramentar, aconselhar, y la conversión, presente en juntar, juramentar, conselhar.

Interesaría saber también, para los casos en que la fluctuación no se ha mantenido en la historia de las lenguas romances (con la obsolescencia de una de las formas del par léxico fluctuante), cuál fue el momento histórico — si en el latín o solo en el vernáculo medieval - y cuáles fueron las razones del solapamiento de una de las for-

47. Para ambas lenguas medievales, en la mayoría de los casos analizados, la adjunción del prefijo $a$ - tiene lugar en el vernáculo, mientras la adjunción de los prefijos de- y en- ocurre en la matriz genolexical latina. 
mas corradicales. Los dos tipos de trayectos prefijales pueden explicarse en función (i) de la estructura morfológica y/o semántica de la base verbal, (ii) de la naturaleza del prefijo (Rio-Torto 2016) y (iii) de factores de naturaleza externa que pueden estar en la base de la coexistencia, durante varios siglos, de dos formas corradicales (Gardani 2015), y de que a partir de determinado momento se cese tal convivencia (Verdelho 1995; Xavier 1999).

A partir del conjunto de datos observados, se puede pensar que las principales motivaciones para la emergencia y conservación de pares léxicos corradicales con y sin prefijos son, como se ha dicho anteriormente, la naturaleza del prefijo - los actuantes son mayormente los preposicionales, que vehiculan matices más nocionales, pasibles de un (progresivo) vaciamiento semántico ${ }^{48}$, algunas veces ya en el latín-, la pervivencia de moldes derivativos heredados de la matriz genolexical latina (la formación de palabras en romance se basa sobre todo en la imitación de modelos formativos ya existentes en latín) y, muy probablemente, algunos factores de naturaleza externa, como la tradicionalización morfolexical incipiente y la ausencia de una normativización gráfica preceptiva en el periodo medieval, época en que surge la mayoría de las voces que erigirán los cuadros de fluctuación léxica.

\section{Conclusión}

Los múltiples patrones coexistentes en el castellano y en el gallego-portugués medievales (y, en menor medida, en la actualidad) para la formación de derivados prefijales incluyen la posibilidad de convivencia —en coocurrencia y/o en concurrencia- de pares corradicales equivalentes. En esa etapa sincrónica pretérita y en su inflexión hacia a periodos históricos subsiguientes es muy heterogénea la representatividad de las soluciones preferenciales (la prefijada frente a la no prefijada) en las dos lenguas. Tal como admitió Rio-Torto (1998b) para algunas formas parasintéticas en el portugués contemporáneo, y Šinková (2013) para las mismas formas parasintéticas en el castellano decimonónico, se puede pensar que son casos episódicos de una variación opcional o libre entre recursos derivacionales de amplia vitalidad en la lengua de antaño, con la convivencia de distintas variantes de una misma raíz sin que se puedan demarcar diferencias de uso o preferencias estilísticas (Sánchez González de Herrero 1992), lo que parece favorecerse, en el período medieval, por un contexto extralin-

48. Vistas retrospectivamente por el hablante/lector/lingüista actual, muchas formas prefijadas en los pares corradicales semánticamente equivalentes no parecen denotar (cuando comparados con sus correlatos) cualquier carga semántica, siendo vacíos. No obstante, la confirmación de esa hipótesis exigiría una colación entre las formas fluctuantes sinonímicas en el momento exacto de su emergencia, lo que es prácticamente imposible de detectar con plena exactitud. Otra hipótesis posible sería pensar que en tales pares, la forma prefijada mantenía alguna carga semántica, por lo menos en su emergencia, aunque fuera meramente expresiva o enfática, por motivos pragmáticos o prosódicos. 
güístico de permisividad/libertad normativa y un contexto intralingüístico de plena creatividad léxica, propios de la emergencia del registro escrito en vernáculo como práctica social efectiva. Algunas de esas formas se han perpetuado en la lengua, sea exclusivamente en el lenguaje popular o en registros dialectalmente marcados (p. ej., alimpar o avoar para el portugués; abastar para el castellano), sea en el léxico general, con sutiles diferencias semánticas o incluso con plena convergencia.

Los datos empíricos muestran que la equivalencia semántica plena con permanencia de ambas formas hasta el presente es muy rara (cf. (de)pendurar (GP), (a)costumbrar (CA)), siendo más frecuente la marcación diastrática, diafásica y/o diatópica de una de las formas (cf. juntarlajuntar, iuntarlaiuntar). Más representados son los patrones de diferenciación semántica plena (sacar vs. as $\left.(s) a c a r^{49}\right)$, equivalencia semántica plena inicial con prevalencia de la forma prefijada (aconselharlaconsejar) o de la forma no prefijada (vedar vs. devedar) y equivalencia/distinción semántica parciales, en la que la forma prefijada (as(s)entar vs. sentar) o la forma no prefijada (cometer vs. acometer) es la más plurisignificativa. La diferenciación semántica plena o la diferenciación semántica parcial corresponden a modelos construccionales de optimización del sistema, según la cual cada derivado (prefijado o no prefijado) conlleva un valor semántico específico identificable. Las situaciones de prevalencia de la forma prefijada o de la forma no prefijada son igualmente clarificadoras de las opciones y de las preferencias de uso en el transcurso histórico. La fluctuación acaba por sufrir erosión con el paso del tiempo, por motivaciones sistémicas — debilitación de las diferencias semânticas entre $a(d)$ - y en-, por ejemplo-y/o por motivaciones sociopragmáticas, como la percepción progresiva de indiferenciación entre las formas prefijada y no prefijada.

Indudablemente, y aquí se concuerda in totum con las conclusiones de Batllori / Pujol (2012), los romances ibéricos en su funcionamiento medieval se plasmaban por tendencias derivacionales multifacéticas inmersas en un continuum latín-romance que explican y justifican la omnipresente variación registrada en las voces corradicales, bien como sus sucesivos y polivalentes cambios funcionales, semánticos y formales, que consubstancian la identidad de los sistemas lingüísticos medievales entonces emergentes.

49. Que es el par corradical más habitual en los corpus verificados, para ambos sistemas lingüísticos. 


\section{Agradecimientos}

Este trabajo se ha realizado al amparo de una investigación financiada por la Coordenaçâo de Aperfeiçoamento de Pessoal de Nivel Superior - Brasil (CAPES) - Código de Financiamento 001 y por el Celga-Iltec - Centro de Estudos de Lingüistica Geral e Aplicada (Universidad de Coimbra).

Se agradecen los comentarios del Consejo de Redacción de Estudos de lingüistica galega y de los evaluadores anónimos, con los que la calidad del presente trabajo mejoró considerablemente. Los errores que persisten son plena responsabilidad de los autores. 


\section{Referencias bibliográficas}

Álvarez Huerto, Olga. 2016. Los verbos con prefixu $a$ - n'asturianu. Lletres Asturianes 114, 11-38.

Batllori, Montserrat \& Isabel Pujol. 2012. El prefijo $a$ - en la formación de derivados verbales. En Emilio Montero Cartelle \& Carmen Manzano Rovira (eds.), Actas del VIII Congreso Internacional de Historia de la Lengua Española. Vol. 1. 659-672. Santiago de Compostela: Meubook/Asociación de Historia de la Lengua Española (AHLE).

Bosque, Ignacio. 1976. Sobre la interpretación causativa de los verbos adjetivales. En Víctor Sánchez de Zavala (ed.), Estudios de gramática generativa del español. 101-113. Barcelona: Labor.

Carvalho, Antonio Carlos Silva de. 2016. Consideraçôes sobre a história e o uso estilístico dos prefixos. Fórum linguistico 13(2), 1240-1254.

Carvalho, Maria José. 2016. Prefixes in the history of Portuguese: a semantic and cognitive approach. Estudos de Lingüistica Galega 8, 45-67.

Castro da Silva, Caio Cesar. 2015. Um breve panorama sobre o léxico em linguística cognitiva. Temiminós 5(1), 24-34.

Cejador, Julio. 2005. Vocabulario medieval castellano. 3.a edición. Madrid: Visor Libros.

Corominas, Joan. 1987. Breve diccionario etimológico de la lengua castellana. 3.a edición. Madrid: Gredos.

Corominas, Joan \& José A. Pascual. 1991. Diccionario crítico etimológico castellano e hispánico. 6 vol. Madrid: Gredos.

Cunha, Antônio Geraldo da. 2010. Dicionário etimológico da língua portuguesa. $4 .^{a}$ ed. revista e atualizada de acordo com a nova ortografia. Rio de Janeiro: Lexicon.

Davies, Mark. Corpus do Português. http://www.corpusdoportugues.org/. (12/05/2018).

Davies, Mark. Corpus del Español. http://www.corpusdelespanol.org/. (15/05/2018).

Dinu, Dana. 2012. Prefix derivation in latin. Studi şi cercetări de onomástica şi lexicologie V(1-2), 125135.

Dolinski, José Tadeu. 1993. Aspectos morfossintáticos, semânticos e estilísticos dos prefixos negativos na formação de palavras em português. Curitiba: Universidade Federal do Paraná. (Dissertação, Mestrado em Letras)

Figueiredo, Cândido de. 1910. Problemas de linguagem. Lisboa: Clássica.

Gago, Francisco (dir.). Hispanic Seminary of Medieval Studies / Biblioteca Digital de Textos del Español Antiguo. http://www.hispanicseminary.org/t\&c/ac/index-es.htm. (08/03/2017).

García-Medall, Joaquín. 1994. La prefijación verbal: un estudio de morfología integrada del español. Valladolid, s.n.

Gardani, Francesco. 2015. Affix pleonasm. En Petter Müller et al. Word-Formation. An International Handbook of the Languages of Europe. 537-550. Berlin/Boston: De Gruyter Mouton.

González Seoane, Ernesto, María Álvarez de la Granja, Ana Isabel Boullón Agrelo, María Rodríguez Suárez \& Damián Suárez Vázquez. Dicionario de dicionarios do galego medieval. http://sli.uvigo. es/DDGM. (15/05/2018).

Graça, Heráclito. 2005. Fatos da linguagem: esboço crítico de alguns assertos do Sr. Cândido de Figueiredo. 3. ${ }^{a}$ ed. Rio de Janeiro: Academia Brasileira de Letras. 
Gutiérrez Cuadrado, Juan. 1993. Sobre algunos desdoblamientos léxicos del siglo xv. En Antiqva et Nova Romania. Estudios lingüisticos y filológicos en honor de José Mondéjar en su sexagesimoquinto aniversario. Vol. I. 331-345. Granada: Universidad de Granada.

Houaiss, Antônio \& Mauro de Salles Villar. 2009. Dicionário Houaiss da língua portuguesa. Rio de Janeiro: Objetiva. (CD-ROM).

Lapesa, Rafael. 1981. Historia de la lengua española. Madrid: Gredos. (Novena edición corregida y aumentada).

Lopes, Mailson. 2013. A Prefixação na primeira fase do português arcaico: descrição e estudo semântico-morfolexical-etimológico do paradigma prefixal da língua portuguesa nos séculos XII, XIII e XIV. Universidade Federal da Bahia. (Tesis de máster inédita).

Lorenzo, Ramón. 1977. La traducción gallega de la Crónica General y de la Crónica de Castilla, vol. II. Glosario. Ourense: Instituto de Estudios Orensanos Padre Feijóo.

Maia, Clarinda. 2002. Dos textos escritos à história da língua. En Brian Head et al. Orgs, História da lingua e história da gramática. 231-249. Braga: Centro de Estudos Humanísticos da Universidade do Minho.

Mattos e Silva, Rosa Virgínia. 2006. O português arcaico: fonologia, morfologia e sintaxe. São Paulo: Contexto.

Mattos e Silva, Rosa Virgínia. 2008a. O português arcaico: uma aproximação. Vol. 1. Lisboa: IN-CM.

Mattos e Silva, Rosa Virgínia. 2008b. Caminhos da lingüistica histórica: ouvir o inaudivel. São Paulo: Parábola.

Mattos e Silva, Rosa Virgínia. 2010. Estruturas trecentistas: elementos para uma gramática do português arcaico. Salvador: EDUFBA.

Menéndez Pidal, Ramón. 2005. Historia de la lengua española. Madrid: Fundación Ramón Menéndez Pidal \& Real Academia Española.

Nunes, José Joaquim. 1989. Compêndio de gramática histórica portuguesa: Fonética e Morfologia. Lisboa: Livraria Clássica Editora. (9. a ed.)

Oliveira, Fernão de. 1536. Grammatica da lingoagem portuguesa. Lixbóa: Germão Galharde. (Edición facsímil disponible en: http://purl.pt/120. Acesso em: 03 set. 2015)

Pascual Rodríguez, José Antonio. 1974. La traducción de la Divina Commedia atribuida a D. Enrique de Aragón: estudio y edición del Infierno. Salamanca: Universidad de Salamanca.

Pena, Jesús. 1995. Sobre la definición del morfema. Lingüistica española actual XVII (2), 129-141.

Pereira, Rui Abel. 2016. Formação de Verbos. En Graça Rio-Torto, Alexandra Soares Rodrigues, Isabel Pereira, Rui Pereira \& Sílvia Ribeiro (eds.). Gramática derivacional do português. 297-350. Coimbra, Imprensa da Universidade de Coimbra.

Pharies, David. 2013. El prefijo es-en castellano y en las otras variedades hispano-romances. En Isabel Pujol Payet, Formación de palabras y diacronía. 109-140. A Coruña: Universidade da Coruña.

Priberam Informática. 2018. Dicionário Priberam da Lingua Portuguesa. 2008-2013. https://www. priberam.pt/dlpo/arremangar. (25/06/2018).

Rainer, Franz. 2015. Mechanisms and motives of change in word-formation. En Peter Müller, Ingeborg Ohnheiser, Susan Olsen, Franz Rainer (eds.), Word-Formation. An International Handbook of the Languages of Europe. 1761-1781. Berlin/Boston: De Gruyter Mouton. 
Real Academia Española. Corpus Diacrónico del Español (CORDE). http://corpus.rae.es/cordenet. html. (04/05/2018).

Real Academia Espańola. 2018. Diccionario de la lengua española. http://dle.rae.es/?w=diccionario. (02/04/2018).

Real Academia Española / Asociación de Academias de la Lengua Española. 2009. Nueva gramática de la lengua española. Vol. 1. Madrid: Espasa Libros.

Real Academia Galega. 2018. Dicionario da Real Academia Galega. https://academia.gal/dicionario. (24/05/2018).

Rio-Torto, Graça. 1998a. Morfologia derivacional: teoria e aplicaçāo ao português. Porto: Porto Editora.

Rio-Torto, Graça. 1998b. Operaçôes e paradigmas genolexicais do português. Filologia e lingüística portuguesa 2, 39-60.

Rio-Torto, Graça. 2004. Morfologia, sintaxe e semântica dos verbos heterocategoriais. En Alexandra Rodrigues, Conceição Anastácio, Graça Rio Torto \& Rui Abel Pereira (eds.), Verbos e nomes em português. 17-89. Coimbra: Livraria Almedina.

Rio-Torto, Graça. 2016. Prefixação. En Graça Rio-Torto, Alexandra Soares Rodrigues, Isabel Pereira, Rui Pereira \& Sílvia Ribeiro (eds.), Gramática derivacional do português. 357-389. Coimbra: Imprensa da Universidade de Coimbra. http/dx.doi.org/10.14195/978-989-26-0864-8.

Romanelli, Rubens Costa. 1964. Os prefixos latinos: da composiçäo verbal e nominal, em seus aspectos fonético, morfológico e semântico. Belo Horizonte: Imprensa da Universidade de Minas Gerais.

Romero Aguilera, Luis. 2009. Aportaciones de la lexicografía al estudio de las variantes formales. En Teresa Bastardín Candón, Manuel Rivas Zancarrón \& José María García Martín (dir.), Estudios de historiografia lingüistica. 713-728. Cádiz: Servicio de Publicaciones de la Universidad de Cádiz.

Salomonski, Eva. 1944. Funciones formativas del prefijo a- estudiadas en el castellano antiguo. Zurich: Ernesto Lang.

Sánchez González de Herrero, Marta de las Nieves. 1992. Derivados verbales contenidos en textos médicos medievales castellanos. En Actas del II Congreso Internacional de Historia de la Lengua Española. Tomo I. 1315-1321, Madrid: Pabellón de España.

Sánchez Martín, Francisco Javier. 2008. Estudio del léxico de la geometría aplicada a la técnica en el Renacimiento hispano. Universidad de Salamanca. (Tesis de doctorado inédita).

Sánchez-Prieto Borja, Pedro. 1993. Alternancia entre el lexema con y sin prefijo en castellano medieval: el verbo. En Actas del II Congreso Internacional de Historia de la Lengua Española. 1323-1336. Sevilla: Arco Libros.

Segura Munguía, Santiago. 2000. Lexicogénesis: derivados y compuestos en la creación del vocabulario latino y castellano. Bilbao: Universidad de Deusto.

Šinková, Monika. 2013. Las formaciones parasintéticas corradicales en el siglo xIx. Études Romanes de Brno 34(2), 183-203.

Varela, Soledad \& Josefa Martín García. 1999. La prefjación. En Ignacio Bosque \& Violeta Demonte (eds.), Gramática descriptiva de la lengua española. Vol. 3. 4993-5038. Madrid: Espasa Calpe.

Varela Barreiro, Xavier (dir.). 2018. Tesouro Medieval Informatizado da Lingua Galega. http://ilg.usc. es/tmilg. (07/04/2018).

Verdelho, Telmo. 1995. As origens da Gramaticografia e da Lexicografia Latino-Portuguesas. Lisboa: INIC. 
Viaro, Mário Eduardo. 2010. Sobre a inclusão do elemento diacrônico na teoria morfológica: uma abordagem epistemológica. Estudos de lingüistica galega 2, 173-190.

Xavier, M. Francisca (dir.). 2003. Corpus Informatizado do Português Medieval. http://cipm.fcsh.unl. pt/. (10/03/2018)

Xavier, M. Francisca, Maria de L. Crispim \& Graça Vicente (orgs.). 1999. Dicionário de verbos portugueses do século 13. Lisboa: Universidade Nova de Lisboa.

Xavier, M. Francisca, Maria de L. Crispim \& Graça Vicente (orgs.). Dicionário de Verbos do Português Medieval. http://cipm.fcsh.unl.pt/verbos/indiceverbos.jsp. (10/05/2018). 